\title{
Desigualdades sociais, pobreza e desenvolvimento sustentável: Novas questões relacionadas aos modelos de conhecimento que fundamentam a ação política*
}

Catherine Laurent*

\section{Resumo}

Para abordar as políticas de enfrentamento da pobreza levando-se em conta a exigência de integração contida na problemática do desenvolvimento sustentável, seria preciso dispor de um conjunto preciso de conhecimentos que nos permitisse realizar um diagnóstico descritivo das desigualdades sociais e das interações específicas envolvendo os vários grupos sociais e o meio ambiente biofísico e construído - no espaço e no tempo. Dispomos realmente desses conhecimentos para levar adiante este projeto? Sabemos como produzi-los? Atualizá-los? Observações convergentes mostram que poucos conhecimentos válidos sobre tais interações encontram-se atualmente disponíveis. Além disso, o acesso aos conhecimentos existentes é geralmente muito problemático e eles são, frequientemente, pouco utilizáveis na prática. Dessa forma, os decisores políticos que julgam necessário dispor de conhecimentos válidos vêem-se geralmente às voltas com inúmeras dificuldades. Diversas pistas têm sido apontadas visando superar essas limitações, articulando melhor a produção de conhecimentos científicos e os processos de tomada de decisão política. A partir de observações, entrevistas e pesquisas bibliográficas, torna-se possível distinguir quatro tipos-ideais das várias maneiras de conceber tais relações: expertise, "evidence based decision", abordagens normativas e abordagens participativas centradas no ideal de co-produção de conhecimentos. Cada um desses tipos corresponde a uma maneira específica de abordar as relações entre a produção de conhecimentos científicos e os processos de tomada de decisão pública, remetendo-nos a um acervo bem delimitado de contribuições disponíveis na literatura técnica sobre o assunto. Cada uma dessas abordagens mantém relações específicas com a empiria e no presente artigo os desafios resultantes são submetidos a uma avaliação crítica.

Palavras-chave: Desigualdades, pobreza, desenvolvimento sustentável, ação política.

* Tradução de Solange Telles Horta Florêncio. Revisão técnica de Paulo Freire Vieira. 


\section{Introdução}

A simples colocação lado a lado dessas três noções - desigualdades sociais, pobreza e desenvolvimento sustentável - levanta inúmeras questões e cada uma delas tem sido objeto de debates complexos e que se articulam apenas parcialmente.

Do ponto de vista da economia política, a conjunção dessas três expressões sugere uma problemática bastante familiar: analisar as desigualdades sociais para melhor compreender as causas da pobreza e melhorar a situação na perspectiva de um desenvolvimento sustentável. Problemática "familiar" visto que a emergência da noção de desenvolvimento sustentável (COMMISSION BRUNDTLAND, 1988) se insere numa história do pensamento do desenvolvimento econômico e social que, desde os anos 1950, articula estas diferentes dimensões, principalmente nos países do Hemisfério Sul. Inúmeros trabalhos descreveram dessa maneira situações onde comparecem círculos viciosos envolvendo a rarefação dos recursos de uso comum, pobreza crescente de uma parcela importante da população e degradação dos recursos naturais. Estas constatações vieram ao encontro e acabaram reforçando um conjunto de trabalhos sobre o eco-desenvolvimento que evidenciavam também a exigência de solidariedade com as gerações futuras e a necessidade de um planejamento pactuado ${ }^{1}$ do desenvolvimento em escala internacional.

Mas, para abordar a pobreza e as políticas de luta contra a pobreza desta perspectiva integrada, torna-se necessário dispor de um conjunto preciso de conhecimentos que nos permitam descrever as desigualdades sociais, como elas são constituídas e especificar as relações específicas envolvendo os diversos grupos sociais e as várias dimensões do meio ambiente, no espaço e no tempo. Contamos com esses conhecimentos para levar adiante esse projeto? Sabemos como produzi-lo? Ou atualizá-lo?

Poderia parecer que sim, na medida em que, com algumas exceções $^{2}$, essas questões têm sido muito pouco debatidas. No

1 Concerté no original. (Nota do Tradutor)

2 Ver, por exemplo, o exame da literatura sobre este tema proposto por Hovland (2003). 
entanto, o déficit de conhecimentos sobre as transformações estruturais das economias dos países do Sul, enfatizado pelo Banco Mundial (1999) no final dos anos 1990, não se reduziu. Pelo contrário: a intenção de redirecionar as políticas de desenvolvimento no sentido da "sustentabilidade" em sentido amplo tornou a situação ainda mais crítica. Dessa forma, o fosso entre o mundo da produção de conhecimentos racionais e o mundo da ação pública tende a aprofundar-se - e isto mais no Sul do que no Norte. Diversas tentativas têm sido feitas para tentar reduzir essa distancia. Elas merecem ser examinadas com cuidado visando iluminar os desafios sociais e políticos envolvidos.

Buscando subsidiar esta análise, eu tratarei sucessivamente de três pontos, a partir de alguns exemplos. Inicialmente, serão retomadas, de forma cursiva, algumas das principais abordagens da relação envolvendo pobreza e desigualdades sociais, com o intuito de indicar em que sentido as exigências do desenvolvimento sustentável implicam a modificação das representações que fazemos geralmente de ambas. Em seguida, na segunda seção, procuramos mostrar como essas exigências condicionam uma evolução das formas de produção de conhecimentos sobre as quais a elaboração de políticas de luta contra a pobreza, afinadas com a perspectiva do desenvolvimento sustentável, poderia apoiar-se. Argumentamos também que esta evolução pode, por sua vez, conduzir a novas formas de desigualdade e exclusão social ${ }^{3}$.

\section{Desigualdades, luta contra a pobreza e desenvol- vimento sustentável: uma relação problemática e necessária}

Desigualdades sociais, pobreza e desenvolvimento sustentável podem ser abordados de diversas maneiras. Quando estas questões são tratadas independentemente umas das outras, é inútil

3 Esta apresentação baseia-se em parte nas reflexões em andamento no âmbito do programa de pesquisa ANR EBP-BIOSOC - Agriculture et développement durable dans les problématiques d'Evidence Based Policies (Laurent Dir. 2006) que associa equipes francesas, brasileiras e sul-africanas. 
tentar coletar dados que nos permitam elucidar suas interações. No entanto, do ponto de vista da formulação de políticas públicas, esta desconexão atinge um ponto-limite com o aumento dos conflitos sociais relacionados à utilização dos recursos naturais.

\subsection{Pobreza e desigualdade social: a recomposição das relações sociais de atividade.}

A questão da pobreza tem sido objeto de intensos debates nas ciências sociais. Contentar-me-ei aqui em retomar uma idéia chave: a heterogeneidade das representações que são utilizadas para fundamentar as políticas de luta contra a pobreza. Com efeito, nem todas compartilham as mesmas exigências relativamente aos dados que seriam necessários para a sua atualização.

Dentre os grandes eixos que estruturam o espaço destas representações, mencionaremos apenas dois, aos quais voltaremos mais tarde:

- a pobreza considerada como fenômeno absoluto ou relativo: a pobreza quantificada em termos absolutos (por exemplo, com base no nível de renda) versus a pobreza considerada em termos relativos (por exemplo, com base no decil das rendas mais baixas de uma dada população), e

- a pobreza considerada como fenômeno objetivo ou subjetivo: a mensuração da pobreza podendo resultar de um acordo firmado entre diferentes observadores (nível de renda ou acesso a alguns recursos) versus a pobreza considerada como fenômeno subjetivo, devendo sempre estar referenciada à maneira pela qual os indivíduos representam o sentimento de pobreza e de exclusão (NUSSBAUM \& SEN, 1993).

Dependendo das premissas adotadas, uma situação de pobreza pode ser abordada em si mesma ou, ao contrário, levando-se em conta sua inserção num dado sistema de interações. Somente nesse último caso a questão das desigualdades emerge como um tópico central. 
A redução da pobreza e a redução das desigualdades são, portanto dois fenômenos distintos e dois objetivos que podem estar dissociados no âmbito das políticas públicas. Até meados dos anos setenta, a concepção das políticas econômicas baseava-se num volume substancial de trabalhos que se referiam a teorias da justiça social - notadamente de inspiração marxista - enfatizando a promoção da igualdade no acesso aos recursos. A partir daí, as contribuições passaram a se concentrar, sobretudo, na utilização dos princípios derivados da teoria da justiça de John Rawls. Tais princípios podem ser utilizados para legitimar os efeitos anti-coesivos de algumas políticas públicas, com base na idéia de que "todos os bens sociais primários, - a liberdade e as oportunidades, a renda e a riqueza, e as bases sociais do respeito individual - devem ser distribuídos de forma igualitária, exceto se uma distribuição desigual do conjunto destes bens, ou de apenas um deles, beneficie os mais desfavorecidos" (RAWLS, 1971, p.303). Desde então, o crescimento das desigualdades econômicas é considerado aceitável apenas (i) se for julgado necessário ao crescimento geral e (ii) se permitir a elevação do nível de renda dos mais pobres ${ }^{4}$.

As concepções da luta contra a pobreza podem, portanto, assumir diferentes perspectivas. Um exemplo recente dessas diferenças pode ser encontrado, por um lado, na resolução da Assembléia Geral das Nações Unidas sobre os objetivos de desenvolvimento do milênio (ONU, 2000), que pressupõe a desconexão entre a busca de redução da pobreza e de redução das desigualdades. E por outro, nas declarações da União Européia que enfatizam a necessidade de maior coesão do conjunto das políticas européias

4 Pontos de vista sustentados especialmente por relações econômicas descritas em trabalhos como os de Kuznets (1955), ou ainda de Kaldor (1956), apesar de inúmeros estudos terem mostrado que nem sempre essas relações resistiam à prova dos fatos. Seria importante ressaltar que mesmo assumindo estritamente a lógica subjacente a esta visão, sua tradução em termos operacionais para avaliar a eficácia de políticas econômicas desvela inúmeros problemas. Por exemplo, quando a melhoria da condição dos mais pobres é mínima, ou quando se torna difícil avaliar se ela é resultante de um simples artifício de mensuração (como no caso da transição do nível de uma agricultura de subsistência gerando renda não quantificada ao nível de um trabalho informal cuja remuneração monetária é quantificada). 
(CE, 1996), uma noção que se refere explicitamente ao problema das desigualdades.

No que se refere aos objetivos de desenvolvimento do milênio, a declaração da assembléia geral das Nações Unidas (ONU, 2000) fixou oito deles para 2015, dos quais o primeiro trata diretamente da necessidade de reduzir a pobreza. Ele contempla a redução pela metade (i) da proporção de indivíduos que vivem com menos de um dólar por dia, e (ii) da proporção de pessoas que sofrem com a fome ${ }^{5}$. Este enunciado omite o problema das disparidades sociais, excetuando-se as referências à busca de igualdade entre homens e mulheres - que comparecem no enunciado de um outro objetivo.

Ao contrário, as questões relativas às disparidades econômicas e sociais e de repartição da riqueza foram colocadas em primeiro plano na agenda política da Europa no final dos anos 1990. A ênfase concedida à noção de coesão visava, com efeito, reforçar a tomada de consciência dos formuladores de políticas (inclusive no setor agrícola) sobre a necessidade de se eliminar as disparidades econômicas entre os cidadãos (coesão econômica) e entre as regiões (coesão geográfica), e também de se reduzir os níveis de exclusão e de marginalização social de indivíduos e grupos (coesão social) $(\mathrm{CE}, 1996)^{6}$.

5 Para uma discussão da pertinência desses indicadores para tratar da questão da pobreza ver, por exemplo, o debate no site www.millenniumdevelopmentgoals. org, ou ainda Ifzal (2007), economista vinculado ao Banco de Desenvolvimento Asiático. Ele estima que o rendimento monetário não seria realmente a variável chave que permitiria mensurar o fenômeno das desigualdades na Ásia: "more generally, household wealth - essentially ownership of physical and financial assets - tends to be unambiguously more unequally distributed than incomes/ expenditures".

6 O artigo 130b do tratado relativo à União Européia convida a Comissão a "apresentar um relatório trienal ao Parlamento Europeu, ao Conselho, ao Comitê Econômico e Social e ao Comitê das Regiões, indicando os progressos obtidos na busca de coesão econômica e social, além da maneira pela qual os instrumentos previstos no referido artigo contribuíram para tanto". Esta noção foi recolocada em primeiro plano em 1996, por iniciativa da Direção Geral das Regiões. Esta última já lamentava naquela época a ausência de uma avaliação integrada dos efeitos das diferentes políticas setoriais, notadamente da PAC. Além disso, apontava que durante a década de 1990 podia se observar um recuo da coesão na maioria dos Estados membros - um fenômeno que se traduzia sobretudo pela ampliação dos desníveis de renda e de desemprego. 
Uma abordagem em termos de coesão social distingue-se claramente de uma abordagem centrada na pobreza, mesmo se considerarmos que a primeira complementa a segunda. Pois pressupõe a intenção de intervir ativamente na dinâmica geradora das desigualdades e na busca de redução das disparidades, em contraste com um padrão de enfrentamento da pobreza definida pelo nível de renda. Esta distinção é relevante, na medida em que uma série de trabalhos recentes comprova que a redução da pobreza (avaliada de maneira absoluta, por exemplo, pelo aumento do nível de renda das pessoas mais pobres) pode coexistir com a deterioração da coesão econômica e social (avaliada pelo aumento das disparidades de rendimentos e dos fenômenos de marginalização). Vários estudos de caso registram a ocorrência desse fenômeno não só no contexto latino-americano (JANVRY \& SADOULET, 2000), mas também em outros continentes $(\mathrm{ONU}, 2007)^{7}$. Eles assinalam a necessidade de se reintegrar, na análise da pobreza e do crescimento econômico, a dinâmica das desigualdades, pois a intensificação das disparidades parece representar uma fonte de conflitos cada vez mais agudos nos próximos tempos (IFZAL, 2007).

Dessa forma, os riscos crescentes de conflitos sociais exigem esforços no sentido de uma integração mais efetiva das análises sobre a pobreza e a dinâmica das desigualdades. Além disso, as evidências empíricas indicam que parece cada vez menos pertinente tentar apreender a dinâmica das desigualdades considerando apenas a renda. Com efeito, certas dimensões fundamentais do nível de vida das famílias, especialmente a habitação, os direitos de acesso à terra ou ao abastecimento de água, podem estar sendo distribuídos de forma muito mais desigual do que a renda. Torna-se necessário, portanto, articular essas diferentes dimensões. Por outro lado, a análise da dimensão ambiental das evoluções sociais é problemática. Sabemos, com efeito, que nem todos os indivíduos mantêm as mesmas

7 Poverty reduction has been accompanied by rising inequality. The benefits of economic growth in the developing world have been unequally shared, both within and among countries. Between 1990 and 2004, the share of national consumption by the poorest fifth of the population in developing regions decreased from 4.6 to 3.9 per cent (in countries where consumption figures were unavailable, data on income were used). 
relações com o meio ambiente. Isto diz respeito não só à dimensão ambiental de suas condições de vida, como sugerem as abordagens centradas na noção de "justiça ambiental" (BOWEN, 2002). Da mesma forma, diz respeito ao acesso e à maneira como são utilizados os recursos naturais. $\mathrm{O}$ exemplo da agricultura mostra que as práticas de cultivo podem variar em função das características das unidades produtivas (tamanho e opções tecnológicas, entre outras), gerando impactos diferenciados sobre a dinâmica dos ecossistemas.

\subsection{Luta contra a pobreza e desenvolvimento sustentável: a ilusão da convergência}

Na abordagem do ecodesenvolvimento, mantida pelo Programa das Nações Unidas para o Meio Ambiente (PNUMA) até o final dos anos 1980, a preocupação relativa à pobreza estava intimamente associada à preocupação pela conservação do patrimônio natural. Este pressuposto foi abalado com a emergência da noção de "desenvolvimento sustentável". Como ressaltaram Godard e Hubert (2002, p.8-9), a nova terminologia foi introduzida não tanto pelo fato de favorecer uma delimitação mais precisa das ações a serem empreendidas. Pelo contrário,

menos preciso nos seus contornos iniciais, menos exigente no seu conteúdo econômico e político, ele [o termo de desenvolvimento sustentável] fixava o alvo a ser alcançado sem avançar muito na especificação dos meios necessários (opções tecnológicas, modalidades de organização econômica e de reforma política etc.). $\mathrm{O}$ termo tornou-se assim amplamente aceito pelos mais diversos atores sociais, que pensavam poder utilizá-lo a serviço de suas causas mas que estariam em desacordo sobre os meios a serem priorizados e as reformas a serem efetivadas. Decorre daí sua ampla aceitação nos mais diversos âmbitos: hoje em dia, as grandes empresas, os Estados e também as ONGs apelam para o ideário do desenvolvimento sustentável.

De fato, as evidências disponíveis comprovam a coexistência de várias interpretações da relação entre os objetivos fixados pelo enfoque de desenvolvimento sustentável e o objetivo de redução da pobreza. Para alguns intérpretes, postulando uma correlação positi- 
va entre os dois objetivos, seria legítimo tratá-los separadamente. Para outros, levando-se em conta as possíveis contradições que poderiam emergir da busca de compatibilização entre os objetivos de conservação do patrimônio natural e de redução da pobreza, seria indispensável associá-los nas análises. Consideremos, por exemplo, a questão relativa à proteção da biodiversidade. Trata-se de um item prioritário na lista de objetivos de desenvolvimento do milênio $(\mathrm{ONU}, 2000)^{8}$. Alguns discursos que superestimam a possibilidade de formação de consensos (IUCN, 2002; SCHERR, 2000) enfatizam uma convergência de objetivos envolvendo a busca de conservação da biodiversidade e a busca de redução da pobreza. Por implicação, as famílias de baixa renda poderiam dispor de melhores condições para se dedicarem às atividades agrícolas, em parte graças ao desenvolvimento do setor de serviços relacionados ao meio ambiente (eco-turismo, restauração e conservação de recursos territoriais, entre outros). É o que sugerem também vários documentos que postulam a integração destes objetivos, mas sem mencionarem suas eventuais contradições. Neste sentido, fundamentam-se em listas de objetivos a serem tratados de forma fragmentada (ONU, 2000). Todavia, num artigo publicado na revista Science, Adams e al. (2004) ressaltaram que, ao contrário do que sugere o termo "pro-poor conservation", o jogo nem sempre resulta em ganhos nos dois sentidos: inúmeros trabalhos mostram que os programas de conservação da biodiversidade geram com frequiência impactos negativos sobre a redução da pobreza e sobre o desenvolvimento das atividades agrícolas. As razões evocadas são as mais diversas. Por exemplo, as coações induzidas por práticas agrícolas tidas como mais favoráveis à proteção do meio ambiente podem ser mais ou menos intensas em função dos tipos de unidades produtivas, e muitas vezes elas impactam mais fortemente as unidades de menor porte. Além disso, as atividades de prestação de serviços ligados à proteção do meio ambiente (como o ecoturismo, entre outros) necessitam de competências e capitais de giro que as tornam com frequiência

8 Objetivo 7: "Assegurar um meio ambiente sustentável”. Meta: "Integrar os princípios do desenvolvimento sustentável nas políticas nacionais; inverter a tendência atual de desperdício dos recursos ambientais". Indicador: "Extensão das áreas protegidas para preservar a biodiversidade (relativamente à superfície total)". 
inacessíveis aos segmentos mais pobres. Finalmente, na medida em que os recursos naturais (água, terras...) estão disponíveis em quantidade finita, o enrijecimento das relações de poder associadas ao crescimento das desigualdades sociais acaba excluindo os mais pobres do acesso aos recursos, mesmo se levarmos em conta que o seu nível de renda monetária vem acusando uma ligeira elevação.

\subsection{O aumento dos conflitos sociais e as aporias das abordagens fragmentadas}

Provisoriamente eliminada da análise, a dinâmica das desigualdades retorna reforçada pelo impacto dos conflitos sociais que ela engendra na dinâmica de apropriação de recursos finitos, pelos conflitos que se multiplicam na disputa pelo acesso aos recursos hídricos, à terra etc. Com efeito, num cenário de elaboração teórica onde comparecem recursos inesgotáveis e um modelo de crescimento ilimitado, pode-se imaginar jogos sem perdedores onde o aumento das disparidades é aceito se for acompanhado pelo aumento do nível de renda dos segmentos mais pobres. Mas levando-se em conta que o mundo real é formado por recursos finitos, as disparidades estão se intensificando e as relações de poder que as acompanham condicionam a exclusão pura e simples dos mais pobres do acesso aos recursos considerados essenciais à sua sobrevivência. Dessa forma, um dos fenômenos marcantes do início do século XXI é a multiplicação dos conflitos que emergem da rarefação relativa dos recursos naturais num contexto de desigualdades crescentes (ONU, 2007). Além disso, não parece mais possível imaginar que tais contradições possam ser superadas unicamente pela via da regulação mercantil, visto que nenhuma prova decisiva atesta que as políticas de liberalização contribuem realmente para a redução da pobreza (WINTERS et al., 2004).

Tornam-se assim mais nítidos os limites dos procedimentos que dissociam os fenômenos da pobreza, das desigualdades e da utilização dos recursos naturais, bem como a necessidade de recolocar a reflexão sobre o assunto numa perspectiva de desenvolvimento sustentável. Trata-se de conciliar, de forma coerente, as exigências colocadas pelo desenvolvimento econômico, pela conservação do meio ambiente e 
pela busca de coesão social, levando-se ainda em consideração, de outra maneira, os efeitos diferenciados das ações que vêm sendo conduzidas atualmente - sem excluir a dimensão do longo prazo e os processos biológicos e climáticos de escopo global. Todos esses diferentes aspectos deveriam ser articulados nas análises, tendo em vista a concepção de formas de intervenção mais adequadas.

\section{Os desafios da transformação dos vínculos entre a produção de conhecimentos e a tomada de decisões políticas visando o tratamento da questão da pobreza na abordagem de desenvolvimento sustentável}

Nesse novo contexto, o uso que se faz dos conhecimentos científicos para a concepção de políticas públicas difere daquele que marcou o período precedente. As interações sobre as precisamos agir são complexas e ainda mal conhecidas, exigindo a consideração de escalas temporais e espaciais muito diversas. Além disso, as decisões a serem tomadas baseiam-se em parte em cenários de efeitos futuros dificilmente previsíveis. Numa situação onde parece necessário compreender melhor as relações entre processos sociais e processos ecológicos, os decisores políticos mobilizam cada vez mais a argumentos de ordem cientifica para justificar e sustentar suas ações quando entram em jogo os objetivos de desenvolvimento sustentável. Mas os conhecimentos necessários nem sempre estão disponíveis.

\subsection{Escassez de dados capazes de permitir o tratamento das relações entre mudanças estruturais, pobreza e desenvolvimento sustentável}

Sabemos que a utilização de conhecimentos inadequados tende a colocar em xeque a própria pertinência dos objetivos fixados por meio das políticas públicas. Trata-se de uma situação que ocorre com frequiência, inclusive no tratamento da questão da pobreza (REDDY \& HEUTY, 2005).

$\mathrm{O}$ fato das pessoas encarregadas de conceber a intervenção pública se basearem em conhecimentos inadequados, recorrendo 
ao argumento da cientificidade dos conhecimentos mobilizados, causa, evidentemente, uma série de problemas. Certamente isto pode ser atribuído a uma simples manipulação: o uso deliberado de um conhecimento sabidamente controverso ou ultrapassado para impor um projeto político. Em todos os domínios de intervenção pública os exemplos são abundantes e o fenômeno tem sido objeto de pesquisas, sobretudo na interface entre a sociologia das ciências, a sociologia política e as ciências políticas. Podemos atribuí-lo também a uma forma de conivência frequiente envolvendo pesquisadores e decisores políticos: os idealizadores de estratégias de intervenção pública, dominantes no campo político, voltam-se naturalmente para aquelas abordagens cientificas consideradas dominantes no campo social da ciência e acabam adotando-as, confiando no saber dos cientistas promovidos a experts e que apontam os conhecimentos supostamente avaliados como os mais adequados. Inúmeros trabalhos de sociologia das ciências ou de ciência política já trataram destes aspectos.

Mas tais registros não são suficientes. Somos forçados a admitir também que os responsáveis pelas decisões se deparam com inúmeras dificuldades em sua busca de conhecimentos válidos para o tratamento de problemas e para a redução dos riscos de intervenção nas situações com as quais eles se defrontam. Como, por exemplo, avaliar o impacto social de uma medida de proteção ambiental, ou os seus possíveis efeitos sobre as estratégias de subsistência dos camponeses mais pobres de uma dada região? Existem poucos conhecimentos disponíveis sobre as interações em pauta, e aqueles que estão disponíveis são dificilmente acessíveis e, com frequiência, dificilmente utilizáveis na prática.

Com efeito, em termos ideais as pessoas às voltas com problemas práticos, e que pretendam tratá-los com base em conhecimentos científicos, esperam que estes últimos:

- $\quad$ sejam pertinentes relativamente às questões levantadas (no caso, as interações envolvendo a dinâmica das desigualdades, da pobreza e dos processos de gestão ambiental) e também utilizáveis nos contextos de ação correspondentes (no caso, os resultados difundidos são realmente confiáveis para esta região? Eles permitem-nos prever os impactos das modalida- 
des de ação planejadas? Resultam em soluções socialmente aceitáveis neste contexto social específico?);

- $\quad$ estejam baseados numa contextualização clara e compartilhada dos fenômenos estudados (por exemplo, definições de pobreza, do leque de configurações de diversidade biológica que seria possível conservar e que se escondem por detrás da noção de "biodiversidade" etc.);

- $\quad$ se reportem a modelos analíticos coerentes, contribuindo para o progresso científico e se beneficiando dos procedimentos de validação assumidos pela comunidade científica;

- $\quad$ incluam mensurações do fenômeno conceitualizado e indiquem de maneira explícita os seus limites, a saber: aproximações possíveis, limites do domínio da validade dos conhecimentos produzidos e indicadores, entre outros (por exemplo, validação geográfica para os dados relativos aos ecossistemas, limites dos procedimentos de amostragem etc.);

- $\quad$ estejam baseados em métodos confiáveis, sobretudo para produzir mensurações livres de vieses ou de pressupostos implícitos passíveis de gerar interpretações distorcidas;

- $\quad$ sejam facilmente acessíveis, isto é, associados a dados de segunda ordem ${ }^{9}$ que nos permitam identificar a que universo de discurso esses conhecimentos se referem e, ao mesmo tempo, que possam nos oferecer uma visão panorâmica de um dado domínio e das controvérsias geradas.

Esta situação ideal parece muito distante da realidade. Mesmo para os indicadores de pobreza e de desenvolvimento sustentável, que têm dado margem a um volume considerável de literatura, nota-se a que ponto eles ainda permanecem aquém desse patamar de precisão e qualidade (NOLL 2002; REDDY \& HEUTY, 2005).

Por exemplo, para compreender as recomposições atuais e os mecanismos que as explicam, seria preciso poder descrever as transformações das relações sociais e dos sistemas de ação (LAURENT \& MOURIAUX, 2006) nesses últimos anos, na medida em que

9 Méta-données no original. (N.T.) 
as estruturas sociais e as desigualdades não são reproduzidas de forma idêntica. Inúmeras monografias mostram que as modalidades de socialização do trabalho e de organização das ações coletivas vêm sofrendo profundas transformações e não se inscrevem mais necessariamente em certas tendências que pareciam estar se configurando no final dos anos 1980 (WORLD BANK, 2008). As análises permitem compreender, entre outras, as mudanças operadas nas topologias familiares, o seu enraizamento multiforme nos diversos setores e territórios e as formas assumidas pela divisão social e técnica do trabalho. No setor da agricultura familiar, por exemplo, em diversos contextos podemos observar não tanto a tendência à modernização especializada que seria de se esperar, mas antes um conjunto de tentativas visando manter as unidades produtivas de pequeno porte, reintegrando-as numa rede familiar que constitui um sistema mais abrangente de ação e de geração de renda. O sistema assim formado associa atividades desenvolvidas em diversos setores e às vezes em regiões muito distantes. Por implicação, a escolha da unidade de base ideal para uma análise rigorosa das mudanças sociais torna-se muito problemática. Se optarmos pelo nível individual, seria preciso levar em conta que a situação momentânea de uma pessoa só pode ser compreendida por meio da análise de uma trajetória complexa que encontra sua lógica num contexto mais amplo. O nível do casal poderia ser outra opção, mas por que não considerar o nível familiar, se as rendas são socializadas numa rede mais ampla? Mas no caso da escolha recair na rede familiar, como apreendê-las? A simples quantificação das transferências familiares é suficiente ou deve ser inserida num conjunto de outros critérios? Todas essas questões fazem parte do acervo clássico da antropologia econômica e, dessa forma, não são novas (GASTELLU, 1979). Mas não deveríamos considerá-las ultrapassadas. Certamente as respostas oferecidas precisam ser atualizadas, se quisermos adaptar os dispositivos de coleta de dados às evoluções contemporâneas e dotar de conteúdos concretos os modelos que visam torná-las inteligíveis. (WHITE, 2002). Em síntese, na ausência de conhecimentos precisos sobre a recomposição das relações sociais vigentes nos sistemas de ação torna-se muito difícil conceber medidas adequadas de luta contra a pobreza. 
O problema não se reduz apenas à carência de conhecimentos confiáveis e úteis para fundamentar os dispositivos de ação. Além disso, muitas vezes esta limitação é camuflada por uma profusão de contribuições, que podem oferecer uma imagem ilusória da existência de um volume excessivo de referências. Assim, por exemplo, com o desenvolvimento da informática e dos modelos de simulação, vem se tornando frequiente a disseminação de representações da realidade sob a forma de mapas acompanhados de dados quantificados e aparentemente muito rigorosos. Mas eles permanecem geralmente marcados por múltiplas aproximações e indeterminações. Quando não se tornam visíveis para os utilizadores potenciais dos mapas, elas podem gerar impressões muito enganadoras. Um exemplo pode ser encontrado na perplexidade experimentada recentemente pela comissão encarregada de avaliar um dos instrumentos norteadores das pesquisas efetuadas pelo Banco Mundial e utilizados por inúmeros governos nacionais. Esta comissão chegou a recomendar que a ferramenta denominada "mapeamento da pobreza" fosse pura e simplesmente retirada de circulação até que a validade dos mapas propostos ${ }^{10}$ seja melhor esclarecida (BANERJEE et al., 2006). O problema criado pela carência recorrente de dados empíricos pertinentes é geral. Num outro contexto, na interseção das problemáticas da pobreza, do meio ambiente e da saúde, (SNOW et al., 2005) mostraram num artigo publicado na revista Nature que a incidência do paludismo seria $50 \%$ mais elevada do que a Organização Mundial da Saúde havia indicado, sem que esta última tivesse conseguido realmente defender a pertinência dos seus dados no debate que se seguiu ${ }^{11}$.

Se os formuladores de políticas públicas voltadas para a redução da pobreza e para o controle de uma doença tão antiga como o paludismo têm dificuldades para se apoiar em dados confiáveis, o que dizer no caso das políticas relativas à integração de processos ecológicos e sociais? Como Carpenter et al. (2006) assina-

10 Esses mapas, destinados às autoridades locais, apóiam-se em um complexo sistema de interpolação geográfica de indicadores de pobreza cuja validade parece difícil, e até mesmo impossível, de ser testada pelos usuários.

11 Mesmo levando-se em conta que eles estão contemplados num dos objetivos de desenvolvimento do milênio (ONU 2000). 
laram recentemente na revista Science, para intervir neste domínio torna-se indispensável elaborar os conceitos básicos e, ao mesmo tempo, organizar a coleta de dados. Mas, também neste caso, as constatações são, ainda hoje, muito preocupantes e, às vezes, contra-intuitivas. Uma análise rigorosa comprova, sobretudo, que uma parte das informações disponíveis hoje em dia é de qualidade inferior relativamente ao acervo acumulado nas décadas passadas. É o caso, por exemplo, das informações coletadas sobre a dinâmica dos sistemas hidrológicos, em consequieencia da desagregação das instituições coletivas que contribuíam na manutenção das redes hidráulicas. A criação de indicadores que integram dimensões sociais e ecológicas das transformações em curso é um desafio a ser superado. Quanto à natureza dos dados que nos permitiriam avaliar o impacto real das políticas ambientais, na opinião de McNeely et al. (2005) "uma coação fundamental ao esforço de tornar mais preciso o que funciona e o que não funciona em matéria de incitações econômicas para a preservação dos ecossistemas é a falta de dados empíricos que permitam confirmar ou refutar o sucesso de uma abordagem, seja ela qual for".

A questão do conteúdo empírico dos conhecimentos obtidos, ou da corroboração dos enunciados factuais, é onipresente nas problemáticas que tratam das tomadas de decisão política sobre temas relacionados ao desenvolvimento sustentável e à pobreza. Sem dúvida, trata-se de um desafio central, caracterizado por um conjunto de linhas de argumentação que não serão desenvolvidas aqui.

Algumas delas dizem respeito às dificuldades conceituais encontradas no tratamento de novas descobertas científicas, bem como na concepção de dispositivos de observação capazes de articular os vários pontos de vista disciplinares gerados no campo das ciências sociais e das ciências da natureza, levando em conta diferentes escalas espaciais e temporais.

Outras dizem respeito à evolução das condições que cercam a coleta dos dados primários necessários à análise das desigualdades sociais e de suas relações com o meio ambiente. Num cenário onde a pesquisa em demografia evolui aceleradamente, a redução de linhas de financiamento governamental para o trabalho de campo 
(a exemplo dos surveys domiciliares), gera uma carência crônica de dados fundamentais, sobretudo nos países do Sul.

Uma terceira linha de argumentação coloca em destaque as transformações operadas no mundo acadêmico e a pertinência dos procedimentos de avaliação instituídos. A cada dia, as universidades produzem um volume cada vez maior de publicações, em detrimento dos meta-dados que poderiam contribuir para tornar mais accessível este imenso acervo de conhecimentos em expansão.

Por outro lado, nos últimos tempos o mundo acadêmico passou a conceder um espaço cada vez maior à criação de modelos de simulação que, fornecendo representações "aproximadas" do real, reduzem ao mesmo tempo as exigências de corroboração empírica para um conjunto significativo de áreas de conhecimento, sobretudo em economia.

\subsection{Alternativas de articulação das esferas de produção de conhecimentos e de tomada de decisão política}

Os decisores políticos que julgam necessário dispor de uma base sólida de conhecimentos corroborados defrontam-se, portanto, com inúmeras dificuldades. Diversas abordagens têm sido propostas visando superá-las, num contexto de busca de opções mais efetivas de integração do esforço de pesquisa científica aos processos de tomada de decisão. Com base em observações, entrevistas e pesquisas bibliográficas podemos indicar quatro tipos-ideais das várias modalidades em jogo de representação destas relações (LAURENT, 2003; KIRSCH \& LAURENT, 2007).

Inicialmente vale a pena ressaltar as concepções construídas sobre o postulado de uma descontinuidade fundamental entre a elaboração científica e as práticas de mudança social. Vista desta perspectiva, a dinâmica dos processos decisórios pressupõe necessariamente a consideração de um conjunto substancial de elementos capazes de viabilizar a formação de compromissos - que constituem a própria essência da ação política. Na trilha de Weber, argumentase que a pesquisa de um modelo de explicação causal das políticas 
econômicas não poderia ambicionar apenas a identificação de seus condicionantes efetivos, na medida em que "o número e a natureza das causas que determinaram um dado evento singular são sempre infinitos, não existindo nas coisas mesmas nenhuma espécie de critério que nos permitiria selecionar uma fração delas como sendo as únicas a serem levadas em conta”.

Nesta primeira situação, um item importante diz respeito ao acesso dos agentes de mudança à base de conhecimentos disponíveis, de tal forma que eles possam combiná-los com outros tipos de conhecimentos e colocar em pratica os procedimentos julgados mais adequados para a formação de acordos. Existem dois tipos principais de resposta visando garantir este acesso.

A primeira, já bem conhecida, é o apelo à competência técnica (expertise) - individual ou coletiva. O sábio, ou um outro tipo de mediador, torna-se o "conselheiro do Príncipe". A figura do expert tem sido objeto de inúmeras análises. As questões suscitadas pelos limites de suas contribuições são inerentes ao exercício que é solicitado.

A expertise funciona como uma espécie de caixa preta e deixa, portanto a descoberto uma grande parte dos elementos que a fundamentam (dados de base, arbitragens realizadas entre diferentes opções, inclusão de saberes profanos etc.). A restituição de uma posição pessoal ou de uma síntese pessoal depende necessariamente da posição do especialista na área de conhecimento em questão e também no campo social. Estes elementos são bem conhecidos. Talvez mais problemático seja o fato de que a noção de expertise encobre situações muito diferentes, dependendo do expert estar ou não em condições de efetuar uma síntese dos conhecimentos existentes e de reproduzir as controvérsias predominantes num dado domínio. Ou que, ao contrário, estando confrontado à rarefação, ou até mesmo à ausência de informações válidas, ele não forneça uma opinião cientificamente corroborada, mas apenas uma opinião que poderia ser qualificada de "expertise fraca" - baseada principalmente na sua experiência e no seu bom senso. No caso das demandas oriundas da necessidade dos decisores de dispor de conhecimentos que permitam avaliar o impacto social de medidas de conservação do meio ambiente, em função da carência de dados essenciais infor- 
mando precisamente as relações entre processos sociais e processos ecológicos, nós nos inserimos com frequiência neste último caso. Mas como já salientamos acima, a partir do momento que existem poucas informações sintéticas disponíveis em áreas ainda muito carentes de dados, pode ser difícil para um decisor localizar os casos onde ele só poderia oferecer uma "expertise fraca".

A segunda opção consiste em promover o recurso a uma utilização a mais criteriosa e racional possível dos conhecimentos científicos disponíveis. Aqui, o "Príncipe" dispõe de novos instrumentos para acessar diretamente os conhecimentos científicos disponíveis. A idéia é facilitar o uso racional desses conhecimentos graças a um jogo de meta-conhecimentos (meta-análises, relatórios sobre o estado-da-arte de critérios explícitos oferecendo um balanço dos avanços e das controvérsias etc.). Mais especificamente, trata-se de promover uma organização coletiva ad hoc para fazer o balanço do que existe, avaliar sua qualidade com base em critérios explícitos, empreender análises globais resgatando resultados fragmentados e propor sínteses dos resultados e das controvérsias que sejam consideradas relevantes para os problemas em pauta. É nesta perspectiva que se inscrevem as abordagens em termos de "evidence based decision" (EBD), uma expressão de tradução difícil, pois o termo "evidence" designa ao mesmo tempo uma "prova", no sentido de prova científica, e um "argumento fundamentado".

As abordagens que reforçam a premissa segundo a qual as decisões devem se basear em conhecimentos validados são oriundas do movimento denominado "evidence based medicine" (GUYATT et al., 1992). Este movimento, por sua vez, estendeu-se para o domínio da política sob o rótulo de "evidence based policy" (DAVIES \& NUTLEY, 2001), passando a ocupar um espaço cada vez maior na literatura sobre o combate à pobreza - como indicam várias publicações do Banco Mundial - e também sobre as estratégias de conservação ambiental (PULLIN, et al., 2004).

Ao que tudo indica, esta reflexão pode ajudar a esclarecer a natureza das relações entre ciência e sociedade em função das exigências que ela impõe e do instrumental metodológico que ela propõe. Ela convida-nos, com efeito, a abrir a caixa preta da expertise, obrigando-nos a explicitar as escolhas e as aproximações que são 
feitas no decorrer da elaboração dos resultados científicos. A intenção é tornar visíveis as controvérsias que são inerentes ao processo de construção de conhecimentos racionais e, além disso, avaliar o "nível de prova" já alcançado para reter as melhores sugestões de tratamento das questões em pauta. Essas metodologias fundamentam o diagnóstico das disfunções evocadas anteriormente (na seção 2.1), relativamente à carência de conhecimentos válidos na construção de políticas públicas capazes de articular os objetivos sociais e ambientais. Para tanto, não é fácil ultrapassar o estágio do diagnóstico. Em termos globais, em função da carência de dados fundamentais, as abordagens do tipo "evidence based decision ", que supostamente seriam capazes de articular as análises das estruturas sociais e das dimensões ambientais, são difíceis de serem concretizadas (SUTHERLAND et al., 2006; CARPENTER et al., 2006) - quer elas se reportem ao impacto das atividades humanas sobre os ecossistemas ou a trabalhos sobre a justiça ambiental, que permanecem limitados por falta de dados empíricos geo-referenciados.

Outras posturas são possíveis e podem ser observadas. Há, com efeito, situações que se fundamentam na idéia de uma possível continuidade entre os níveis da produção científica e das práticas de mudança: quando a produção científica é normativa com relação à política ou quando os objetivos das políticas são internalizados na estrutura teórica.

Emerge assim uma terceira situação, na qual o cientista se mostra como preceptor normativo para a prática (ou ainda a situação onde aquele que se apresenta como preceptor o faz em nome de uma exclusiva e insuperável "verdade" científica). Aqui, o cientista assume o lugar do "Príncipe".

Pode-se considerar que no campo da decisão política, a produção científica é normativa (i) quando políticos e cientistas estão de acordo sobre o fato de que a teoria pode fundamentar uma decisão política racional e (ii) quando uma teoria pode fornecer, com base numa ordem de preferência explicita, prescrições coerentes com sua estrutura lógica. Exemplos desta postura podem ser encontrados em economia e em ecologia. É o que se observa, por exemplo, no campo da defesa do meio ambiente quando os especialistas em biologia da conservação se colocam como preceptores em nome 
da "saúde dos ecossistemas" (cf. debate sobre o tema na revista Conservation Biology; LACKEY, 2007; SCOTT et al., 2007).

Uma tomada de posição com este perfil levanta inúmeras objeções, porque tende a negar a especificidade da regulação política e a destituir as instâncias políticas do seu poder de tomada de decisão. Poder-se-ia pensar que estas objeções conduzem necessariamente a um retorno das situações (que reconhecem a descontinuidade irredutível entre modelo e realidade, além da necessidade de arbitragens introduzindo elementos "não científicos"), mas não se trata disso. Vale a pena ressaltar que um dos "atrativos" da visão normativa - do ponto de vista orçamentário - é que ela permitiria aliviar os custos da produção de conhecimentos voltada para uma avaliação precisa das consequiências sociais de cenários alternativos de gestão ambiental. Outra "vantagem" para os decisores diz respeito à transferência da responsabilidade pelas decisões aos cientistas, quando elas acenam com a probabilidade de riscos importantes

O exame deste relacionamento específico entre a produção de conhecimentos científicos e as tomadas de decisão política permitenos evidenciar a existência de uma assimetria fundamental entre economia e ecologia. Com efeito, enquanto as abordagens normativas oriundas da economia têm sido alvo de críticas recorrentes por parte dos partidos políticos, dos sindicatos e das associações civis, o cenário mostra-se menos contundente no caso das disciplinas vinculadas às ciências da natureza e que vêm sendo mobilizadas na formulação de políticas ambientais. A título de exemplo, num contexto onde uma população extremamente pobre pretende fazer valer os seus direitos de acesso à terra (populações negras que pedem a restituição de terras no quadro da reforma agrária sul-africana), constata-se que certos lobbies ambientalistas podem chegar a bloquear o processo mediante argumentos pretensamente científicos, sem que as diversas instâncias de defesa destas populações, muitas vezes apoiadas numa longa tradição de luta política, sejam capazes de extrair desses argumentos itens passíveis de contestação (KEPE et al., 2005; LAURENT, 2005).

Uma quarta situação - a co-produção de conhecimentos - vem se consolidando nos últimos anos, de maneira expressiva, na esfera do planejamento do desenvolvimento sustentável. Neste caso, a pro- 
dução de conhecimentos internaliza as arbitragens dos formuladores de políticas públicas (ou de outros tipos de agentes sociais) na sua própria arquitetura conceitual. Podemos solicitar, por exemplo, a diferentes parceiros (considerados como porta-vozes de diversos grupos sociais, e até mesmo de outras espécies vivas - como as aves) ou a indivíduos no processo de experimentação com abordagens participativas, que contribuam na elaboração dos relatórios finais. Às vezes, os parceiros não-cientistas podem ser mobilizados inclusive para oferecer os parâmetros de um modelo (ou os elementos que permitiriam calibrá-lo) ou mesmo as suas variáveis centrais. Estes procedimentos mais ou menos formalizados visam garantir uma melhor pertinência dos conhecimentos produzidos e, em alguns casos, constituem uma estratégia para contornar a ausência de dados válidos que nos permitiriam descrever uma fração do fenômeno material considerado. Por exemplo, poderíamos substituir uma análise - onerosa - dos interesses dos diferentes grupos sociais preocupados pela gestão de uma dada bacia hidrográfica por uma oficina de dramatização, onde o conjunto de participantes seria convidado a simular os papéis desempenhados por estes grupos.

Esta nova forma de produção de conhecimentos apresenta-se sob várias formas: "produção científica de tipo 2" (GIBBONS et al., 1994), "ciência pós-normal” (FUNTOWICZ \& RAVETZ, 2003), modelização de acompanhamento (ETIENNE, 2003) etc. Estas diferentes formas diferenciam-se em função do nível de implicação de parceiros leigos na construção dos conhecimentos e dos critérios utilizados na avaliação dos mesmos. Numa visão moderada da produção científica - ou do tipo 2 - a idéia é de agregar aos critérios clássicos de validação desses produtos outros critérios que levem em conta a pertinência social dos conhecimentos produzidos - além de produzir conhecimentos por meio de procedimentos que permitam garantir esta pertinência. Por outro lado, numa visão mais radical - ou de uma ciência pós-normal - o objetivo não é produzir conhecimentos mais verdadeiros que os precedentes ${ }^{12}$ (FUNTOWICZ, RAVETZ, 1994) e sim conhecimentos compartilhados:

12 "The new problems of ecological economics call for a " post-normal science. In this, science is no longer imagined as delivering truth" (p.197) 
em todos os casos, trata-se, com efeito, de construir uma representação, de compartilhá-la e depois de formalizá-la sob uma forma particular: modelizações "inconscientes" (diagnósticos participativos unicamente verbais, representações cognitivas de um expert sobre a situação) e modelizações mais explícitas (mapas, sistemas de informação, modelos informatizados...) (COLLECTIF COMMOD, 2005 , p.167) ${ }^{13}$.

Tais procedimentos de co-produção de conhecimentos são aqueles que têm sido apresentados com mais frequiência como uma alternativa ao funcionamento tradicional da ciência, como a única capaz de gerar conhecimentos realmente utilizáveis em situações marcadas por incertezas - soluções que, mesmo não sendo consideradas como as melhores ${ }^{14}[14]$ - caracterizam-se pelo grau de consenso que conseguem forjar. Elas são apresentadas também, com frequiência, como uma alternativa para tomadas de decisão política convencionais, ou como uma dimensão central dos novos modos de governança que tendem a se basear na mobilização de competências locais - como sugere, por exemplo, uma publicação recente da $\operatorname{OCDE}^{15}$.

As demandas suscitadas por essas abordagens são muito numerosas para serem desenvolvidas aqui. Na sequiência, nós nos contentaremos apenas em enunciar cursivamente algumas delas, visando contrastá-las com as abordagens precedentes.

Antes de qualquer coisa, tais demandas dizem respeito às desigualdades que comprometem a viabilidade de um cenário de

13 Este texto foi objeto de inúmeras respostas publicadas na revista Natures Sciences Sociétés.

14 "O que se busca não é a qualidade da escolha, mas a qualidade do processo que conduziu a ela. Não se trata de encontrar a melhor solução, mas de proporcionar os meios para se levar em conta, da melhor maneira possível, as incertezas da situação examinada em comum" (Collectif Commod, 2005, p.167).

15 "O novo paradigma rural passa por uma reorganização da maneira de conceber as políticas públicas e sua implementação. A elaboração de uma política de desenvolvimento rural destinada a diversas regiões ou coletividades implica em se reunir os conhecimentos apreendidos por um amplo leque de atores públicos e privados. Na medida em que as estruturas administrativas hierárquicas tradicionais são consideradas como provavelmente pouco propícias a uma concretização eficaz deste tipo de política, impõe-se a realização de certos ajustes tanto no âmbito do poder central quanto no das autoridades locais, bem como entre os diferentes níveis da administração" (OCDE 2006, p.6). 
co-produção. A pobreza extrema induz a marginalização social e a exclusão, inclusive para operações de desenvolvimento. Carentes muitas vezes do nível de capital social e capital cultural considerado indispensável, incluindo-se nisto a capacidade de organização das ações coletivas, os mais pobres são frequientemente ignorados nos convites para procedimentos de concertação multi-atores. Mesmo quando eles estão presentes, como assinala Sudhirendar (2006), no que diz respeito às abordagens participativas, não basta decretar que diversos porta-vozes serão associados para que sejam equacionadas as questões de representação democrática que vêm sendo investigadas pelos cientistas políticos há tanto tempo; para que nos procedimentos de referência as relações de poder entre grupos sociais desapareçam e para que os protagonistas disponham de possibilidades de expressão e de convencimento equivalentes.

Na sequiência aparece a questão do "consenso". Não basta que uma solução cooperativa seja encontrada para que as relações de dominação e os conflitos de interesse desapareçam. A noção de "consenso" nos leva a crer que o acordo já foi conquistado, ao passo que a noção de "compromisso" marca a distancia que existe entre um acordo imediato e os possíveis conflitos de interesse que o subentendem. O que revelam os "consensos" estabelecidos num contexto de co-produção de conhecimentos? A adesão? Ou simplesmente o grau de adaptação a uma situação desigual e a impossibilidade de exprimir os desacordos? ${ }^{16}$ A resposta é importante na medida em que nos perguntamos se a implantação de abordagens visando produzir soluções consensuais não poderia ser interpretada como uma forma de engenharia da estabilização das relações de poder existentes.

Finalmente, devemos levar em conta a natureza dos conhecimentos produzidos. Trata-se ainda de conhecimentos científicos quando passam a ser mesclados conhecimentos válidos e diversas

16 Reencontramos aqui um debate já antigo sobre a interpretação dos indicadores subjetivos da condição de pobreza. Quando se quantifica a pobreza tomando por base as aspirações das pessoas envolvidas, o que está sendo medido exatamente? Suas aspirações mais profundas? Ou simplesmente seu grau de adaptação a situações limites, os limites de sua capacidade de pensar de outra forma o seu futuro? (ERICKSON, 1993 apud NUSSBAUM \& SEN, 1993). 
modalidades de saberes profanos...? Em alguns casos (especialmente em algumas experiências de modelização de acompanhamento), trata-se antes de um novo tipo de ferramenta imaterial, destinada a auxiliar nos processos de tomada de decisão, mas cujos resultados factuais não podem servir de base para uma construção científica ulterior (KIRSCH \& LAURENT, 2007).

\section{Conclusão}

As quatro formas ideais-típicas que foram descritas correspondem a diferentes maneiras de abordar as relações entre a produção científica e os processos de tomada de decisão política. Todas elas remetem ao acervo de conhecimentos disponíveis sobre a temática da pobreza e das desigualdades sociais na construção de estratégias de desenvolvimento sustentável. Evidentemente, a realidade é marcada pela existência de situações híbridas. Entretanto, cada uma destas formas de pensar o inter-relacionamento entre ciência e decisão política contém desafios específicos, que merecem ser analisados de maneira mais profunda. Com efeito, podemos nos perguntar se, em termos contra-intuitivos, a forma "co-produção de conhecimento" não seria aquela que, ao longo do tempo, correria os maiores riscos de bloquear o controle democrático da utilização de conhecimentos científicos, se por acaso ela chegar a adquirir um estatuto hegemônico no campo do planejamento do desenvolvimento sustentável.

Para compreender todas as implicações das evoluções em curso, torna-se necessário recolocar em perspectiva - e colocar provisoriamente à distância - as abordagens da sociologia das ciências (no sentido da science studies) que abordam as relações entre conhecimentos e decisão política adotando um princípio metodológico de simetria dos saberes. Esta metodologia permite-nos analisar uma situação de tomada de decisão - por exemplo, a criação de um parque natural (SELMI, 2006) - concedendo atenção tanto aos saberes científicos disponíveis quanto aos conhecimentos oriundos da experiência, e/ou ligados a diversos tipos de crenças. Inúmeros trabalhos demonstraram o valor heurístico deste princípio metodológico para analisar a posteriori a maneira pela qual se configura um processo de tomada de decisão, bem como o lugar que nele ocupam 
os diferentes tipos de saberes ou, para não esquecer a expressão de alguns autores - os diferentes tipos de interesses subjacentes - por ocasião de uma concertação coletiva (CALLON, 1989). Por outro lado, isto não significa que na prática todos os tipos de conhecimentos possam ser utilizados de maneira equivalente.

Dessa forma, os saberes tradicionais merecem ser levados em conta por ocasião da análise de uma dada situação, mas isto não significa que eles possam ser colocados no mesmo plano dos conhecimentos científicos já corroborados quando se trata de agir, mesmo que seja útil analisar o papel que eles desempenham nas tomadas de decisão, ou conceber um dispositivo para testar sua eficácia com relação a certos objetivos dados.

Não se levando em conta esta demarcação, pode-se colocar num mesmo plano as idéias recebidas de diversos "parceiros" (por exemplo, sobre os comportamentos dos mais pobres) e as análises fundamentadas em protocolos rigorosos de observações empíricas; ou as opiniões de experts que "estimam" a amplitude quantitativa de alguns fenômenos e os resultados de dispositivos de mensuração que explicitam os limites de validade de seus resultados; ou ainda modelos explicativos sensíveis à necessidade de comprovação dos fatos e aqueles que só se preocupam com a coerência de sua axiomática etc.

Ora, uma coisa é trabalhar na elaboração de instrumentos imateriais de ajuda às tomadas de decisão que permitam explorar cenários possíveis de intervenção, e outra assimilar os conhecimentos assim produzidos aos conhecimentos científicos já validados; ou considerar que este tipo de procedimento possa se colocar como uma alternativa a um processo de tomada de decisão política que procura apoiar-se nos "jogos de conhecimentos" válidos que assumem as controvérsias inerentes à sua construção. Uma evolução com este perfil seria duplamente prejudicial.

De imediato, ela anularia toda a legitimidade do critério de comprovação factual para os instrumentos que pretendem desempenhar um papel relevante nos processos de tomada de decisão política. Ora, ao contrário, como indicamos acima (na seção 2.1), torna-se necessário insistir na importância de se criar (ou restabe- 
lecer) bases de conhecimentos que nos permitam dotar as representações das relações sociedade - meio ambiente de conteúdos empíricos confiáveis. Sobretudo para tornar mais visível a situação efetiva dos mais pobres e contribuir para esta situação que seja levada em conta nas políticas de desenvolvimento sustentável que visam conciliar, de maneira coerente, as exigências próprias ao fomento do desenvolvimento econômico, à conservação do meio ambiente e ao fortalecimento da coesão social.

Na ausência de um esforço apontando nessa direção, a produção de conhecimentos racionais sobre estes temas poderia ser gravemente afetada num prazo relativamente curto. $\mathrm{Na}$ situação atual de penúria de dados relativos às recomposições das relações sociais nos sistemas de ação e sobre suas relações com a conservação ambiental, é forte a tentação de substituir conhecimentos científicos cuja produção é onerosa, e de uso às vezes problemático, por modalidades de conhecimentos oriundos de procedimentos participativos ou por representações oriundas de modelos de simulação que criam uma ilusão de precisão e/ou de comprovação factual efetiva. Se conhecimentos originários de procedimentos de co-produção podem às vezes contribuir para uma melhor utilização dos conhecimentos científicos na prática, seria importante reconhecer que eles não podem pretender substituir estes últimos. Oriundos de um procedimento que mistura conhecimentos válidos e outras formas de conhecimentos, seu uso se interrompe na etapa da prática. Por implicação, a progressão dos saberes corroborados pela comunidade científica permanece necessária para alimentar as diferentes formas de ajuda aos processos de tomada de decisão política e, ao mesmo tempo, permitir a progressão dos programas de pesquisa.

Por outro lado, não se pode negar que as relações entre ciência e sociedade estão "sob stress" (LESCHNER, 2005, NOWOTNY, 2005). O desenvolvimento de abordagens em termos de "evidence based décision" vem tornando ainda mais visíveis os hiatos que se criam entre as diferentes disciplinas científicas, entre a produção científica e as práticas de mudança etc. Disto resulta, aliás, certa desconfiança no que diz respeito a estas abordagens em termos de EBD, que lembra a propensão de alguns 
imperadores chineses em matar os mensageiros que traziam más notícias. Mas deve-se incriminar a abordagem ou escolher debruçar-se sobre o problema que ela revela? A segunda opção parece preferível tanto quanto as evoluções observadas nas relações ciência - sociedade parecem ser, elas mesmas, portadoras de novas formas de desigualdade e de exclusão social.

Recebido em 15.12.2008

Aprovado em 20.1.2009

\section{Referências}

ADAMS, W.M.; AVELLING, R.; BROCKINGTON, D.; DICKSON, B.; ELLIOT, J.; HUTTON, J.; ROE, D.; VIRA B. \& WOLMER W. Biodiversity conservation and the eradication of poverty. Science. 306, 2004.

BANERJEE, A.; DEATON, A.; LUSTIG, N.; ROGOFF, K. avec HSU, E. et al . An evaluation of World Bank Research, 1998-2005. 164 p, 2006.

BANQUE MONDIALE. Le savoir au service du développement (Rapport sur le développement dans le monde, 1998). Banque mondiale, Washington D.C, 1999.

BOWEN, W. An Analytical Review of Environmental Justice Research: What Do We Really Know? Environmental Management, Vol. 29, No. 1, 2002.

CALLON, M. Éléments pour une sociologie de la traduction : la domestication des coquilles Saint-Jacques et des marins-pêcheurs dans la baie de Saint-Brieuc, Année sociologique, 36, 1989.

CARPENTER, S.; DEFRIES, R.; DIETZ, T.; MOONEY, H.; POLASKY, S.; REIDS, W. \& SCHOLES, R. Millenium Ecosystem assessment : research needs. Science, vol. 314, 2002.

CE (Commission Européenne). Premier rapport sur la cohésion économique et sociale. 159 p., 1996.

COLLECTIF COMMOD, . La modélisation comme outil d'accompagnement. Natures, Sciences, Sociétés. 13, 165-168, 2005.

COMMISSION mondiale sur l'environnement et le développement, dite Commission Brundtland. Notre avenir à tous, Montréal, Editions du fleuve, 1988. 
DAVIES, H.T.O. \& NUTLEY, S.M. Evidence-based policy and practice: moving from rhetoric to reality. Proceedings of the Third international Interdisciplinary Evidence-based Policies and Indicator Systems Conference, 2001.

ETIENNE, M. Sylvopast: a multiple target role-playing game to assess negotiation processes in sylvopastoral management planning. Journal of Artificial Societies and Social Simulation vol. 6, no. 2, 2003.

FUNTOWICZ, S. \& RAVETZ, J. The worth of a songbird: ecological economics as a post-normal science. Ecological economics, 10, 1994.

. Post-Normal Science, 2003. [www.ecoeco.org/ publica /encyc_entries/ PstNormSc.doc]

GASTELLU, J.M. Mais où sont donc ces unités économiques que nos amis cherchent tant en Afrique?. Abidjan, Côte d'Ivoire, ORSTOM, 1979.

GIBBONS, M. ; LIMOGES, C. ; NOWOTNY, H. ; SCHARTZMAN, S. ; SCOTT, P. \& TROW, M. The new production of knowledge. the dynamic of science and research in contemporary societies. London, Thousand oaks, New Delhi: Sage, 1994.

GODARD, O. \& HUBERT, B. Le développement durable et la recherche Scientifique à l'INRA. INRA. Bilan et perspectives, 2002.

GUYATT et al. Evidence-Based Medicine. A new approach to teaching the practice of Medicine. JAMA, v. 268, n.17.

HEALY, S. Extended peer communities and the ascendance of postnormal politics. Future, 31, 1999.

HOVLAND, I. Knowledge Management and Organisational Learning: An International Development Perspective. An Annotated Bibliography. London: Overseas Development Institute, 2003.

IFZAL, A. Inequality in Developing Asia. Keynote Speech of the Chief Economist of the Asian Development Bank at the Finalization Workshop for the Study on PRC's Inclusive Growth, 2007. [http:// www.adb.org/Documents/Speeches/2007/sp2007036.asp]

IUCN. Beyond Rhetoric: Putting Conservation to Work for the Poor. Galnd, Switzerland, 2002. 
JANVRY, A. \& SADOULET, E. Main investment in the rural poor into Good Business: new perspectives for Rural Development in Latin America. Working paper for the Conference on developing the rural Economy and reducing Poverty in Latin America and the Caribbean, New Orleans, 24 March, 2000.

KEPE, T.; WYNBERG, R. \& ELLIS, W. Land reform and biodiversity conservation in South Africa: complementary or in conflict? International Journal of Biodiversity Science and Management, 1, 3-16, 2005.

KALDOR, N. Alternative theories of distribution. Review of economic studies, 23, 83-100, 1956.

KIRSCH, M.; LAURENT, C. Scientificity, policy making and empirical validity of knowledge: new issues? Communication pour le colloque mondial de philosophie des sciences. Pekin. Août, 2007.

KUZNETS, S. Economic growth and income inequalities. American Economic review, vol.45, 1-28, 1955.

LAURENT, C. Biodiversity conservation against small-scale farming? Towards new types of land crises. communication à la conférence internationale "The Changing Politics of Land in Africa : domestic policies, crisis management and regional norms" (London School of Economics, IFAS, FAO, Université de Pretoria). 28-29 November 2005, Pretoria, South-Africa, 2005.

LAURENT, C. (Dir.) Validité des connaissances scientifiques et intervention publique : le cas de l'agriculture dans le développement durable. Projet ANR EBP-BIOSOC. 20017-2010. 2006.

LESHNER, A. Where Science meets society. Science, 307, 2005.

LOSCH, B. ; PERRAUD, D. ; LAURENT, C. \& BONNAL, P. Régulation sociale et régulation territoriale de l'agriculture dans les pays du Groupe de Cairns et de l'ALENA. Programme Multifonctionnalité INRA-CIRAD-CEMAGREF. Les cahiers de la multifonctionnalité, $n^{\circ} 6,2004$.

MACNEELY et al. In: CHOPRA, K.; LEEMANS, R.; KUMAR, P.; \& SIMONS, H. (Eds.) Ecosystems and Human Well-being, vol.3, Policy responses. Washingtom DC: Island Press (Millenium Ecosystem Assessment), 2005. 
NOLL H. Social indicators and quality of life research background. Achievement and current trends. In: GENOV, N. (Ed.) Advances in sociological knowledge over half a century. Paris: International Science Council, 2002.

NOWOTNY, H. High and low costs Realities for Science and Society. Science, 308, 2005.

NUSSBAUM, M. \& SEN, A. (Dir.) The quality of life. Oxford, Clarendon, 1993.

OCDE. Réinventer la politique rurale. Synthèse de l'OCDE. 2006.

ONU. Assemblée générale des Nations Unies. Déclaration du Millénaire. Résolution adoptée par l'Assemblée générale, Cinquantecinquième session. 2000.

ONU. Rapport sur les objectifs du millénaires pour le développement. 2007. PULlin, A.S.; KNIGHT, T.M.; STONE, D.A. \& SHARMAN, K. Do conservation managers use scientific evidence to support their decision-making? Biological conservation. 2004.

RAWLS, J. A theory of justice. Londres: Oxford University, 1971.

REDDY, S.G.; HEUTY, A. Achieving the Millennium Development Goals: What's Wrong with Existing Analytical Models?. Harvard Center for Population and Development Studies, Vol. 14, No. 3, 2005. Available at SSRN: http://ssrn.com/abstract $=802804$

SCHERR, S.J. A downward spiral? Research evidence on the relationship between poverty and natural resource degradation. Food Policy 25 (4), 2000.

SCOTT, M.; RACHLOW, J.; LACKEY, R.; PIDGORNA, A.; AYCRIGG, J.; FELDMAN, G.; SVANCARA, L.; RUPP, D; STANISH, D. \& STEINHORST, K. Policy advocacy in Science: Prevalence, perspectives, and Implications for Conservation Biologists. Conservation Biology. vol. 21, n $1,2007$.

SELMI, A. Administrer la nature. Le parc national de la Vannoise. Ed Quae /maison des sciences de l'homme, 2006.

SNOW, R.; GUERRA, C.; NOOR, A. MYINT, H. \& HAY, S. The global distribution of clinical episodes of Plasmodium falciparum malaria. Nature, vol 434, 214-217. Debat in Nature vol. 437, 2005. 
SUDHIRENDAR, S. Sudhirendar S. 2006. People vs. Poverty: Powering through partnership. Future. 39, 625-631.

WEBER, M. Le savant et le politique. Préface de R.Aron. 1959/1919.

WINTER, A.; MCULLOCH, N. \& MCKAY, A.Winter A., McCulloch N., McKay A. Trade Liberalization and Poverty : The Evidence so Far. Journal of Economic Litterature, Vo.XLII, p.72-115, 2004.

WHITE, H. Combining quantitative and qualitative approaches in poverty analysis. World developement. v.30, n.3, 2002.

WORLD BANK. (Forthcoming). World Bank report 2008. Agriculture for development.

SUTHERLAND, W.J. et al. 2006. The identification of 100 ecological questions of high policy relevance in the UK. Journal of Applied Ecology, 43 (4), 2006.

\begin{abstract}
Social inequalities, poverty and sustainable development. New questions linked to models of knowledge that serve as the basis for political action.

In order to discuss policies for confronting poverty while taking into account integration demands posed by the problematics of sustainable development, we must dispose of a precise type of knowledge that enables us to carry out a descriptive diagnosis of the social inequalities and specific interactions that involve a variety of social groups and the bio-physical and constructed environment - in time and space.. Do we truly dispose of the knowledge we need to carry out such a project? Do we know how to produce it? How to bring it up-to-date? Converging observations have shown us that at present, valid knowledge on this interaction is scarce. Furthermore, access to existing knowledge is generally very problematic and possesses scant practical applicability. Thus, political decision-makers who consider this knowledge necessary must generally face a wide range of difficulties. A number of clues that indicate a way beyond these limitations have been discovered and can provide a better articulation of scientific knowledge political decision-making. Through observations, interviews and bibliographic research, it has become possible to distinguish between four ideal-types of ways of understanding these relationships: expertise, "evidence-based decision", normative approaches and participatory approaches centered around the ideal of co-production of knowledge. Each
\end{abstract}


one of these ideal types corresponds to a specific way of approacing the relations between the production of scientific knowledge and processes of public decision-making, which refer us back to a well-defined corpus of contributions available in the technical literature on this issue. Each one of these approaches maintains specific relations with empirical reality and results in challenges that we subject here to critical evaluation.

Keywords: Inqualities, poverty, sustainable development, political action. 
